\title{
Representações Poéticas da Morte nas Narrativas Midiáticas: Um Conto Chinês ${ }^{1}$
}

\section{Poetic Representations of Death in Media Narratives: Chinese Take-Out}

\author{
Míriam Cristina Carlos Silva \\ Universidade de Sorocaba \\ $<$ miriam.silva@prof.uniso.br>
}

\author{
Como citar este artigo (How to cite this article): \\ SILVA, Míriam Cristina Carlos. Representações Poéticas da Morte nas Narrativas Midiáticas: Um Conto Chinês. \\ Revista Famecos, Porto Alegre, v. 25, n. 2, p. 1-17, maio, junho, julho e agosto de 2018: ID27475. \\ DOI: http://dx.doi.org/10.15448/1980-3729.2018.2.27475.
}

\section{RESUMO}

Este artigo é parte de uma pesquisa amparada pela Fundação de Amparo à Pesquisa do Estado de São Paulo (FAPESP), com o tema "Representações Poéticas da Morte nas Narrativas Midiáticas". Buscase compreender: as representações da morte em narrativas midiáticas; os conceitos de comunicação e incomunicabilidade, em suas relações com a cultura e a consciência da morte; a possibilidade de uma comunicação poética como forma de representação / construção complexa do fenômeno da morte e, entendendo-seocinema como mídia, as representações da morte contidas nestas narrativas, a partir de seus aspectos poéticos. Utiliza-se: a pesquisa bibliográfica; a exploratória, para delimitação do corpus; a análise das narrativas selecionadas, no caso deste artigo, do filme argentino Um Conto Chinês (2011, Sebastián Borensztein). Com as análises, são desvelados aspectos poéticos nas representações da morte, que podem apontar para a possibilidade de uma comunicação poética, norteadora de nossa hipótese sobre o poético como forma complexa de representação / construção do fenômeno da morte nas narrativas midiáticas.

Palavras-chave: Representações poéticas da morte. Narrativas midiáticas. Um Conto Chinês.

\section{ABSTRACT}

This article is part of a research supported by FAPESP, whose theme is "Poetic Representations of Death in Media Narratives". It seeks to understand: the representations of death in media narratives; the concepts of communication and incommunicability, in their relations with culture and the consciousness of death; the possibility of a poetic communication as a form of complex representation / construction of the phenomenon of death and, understanding the cinema as media, the representations of death contained in these narratives, from their poetic aspects. It's used: the bibliographic research; the exploratory, for delimitation of the corpus; the analysis of the selected narratives, in the case of this article, the argentine film Chinese Take-Out (2011, Sebastián Borensztein). With the analyzes, poetic aspects are revealed in the representations of death, which can point to the possibility of a poetic communication, guiding our hypothesis about the poetic as a complex form of representation / construction of the phenomenon of death in the media narratives.

Keywords: Poetic representations of death. Media narratives. Chinese Take-Out.

1 Uma primeira versão deste trabalho foi apresentada como Comunicação Oral no Il Simpósio Comunicação e Cultura: Memória e História Oral, realizado na Universidade de Colima, México, em abril de 2017. 


\section{Introdução}

Este trabalho parte da compreensão da comunicação como evento raro, denominado acontecimento comunicacional (Marcondes Filho, 2004, 2008a), e da morte como princípio fundador da cultura (Morin, 1997), que nos leva à tentativa de comunicação, já que comunicamos para nos enganar acerca da consciência de nossa mortalidade (Flusser, 2007). Somos afetados pelo outro, em processos de vinculação, nos quais a mídia intenta ser a ponte que procura romper o abismo que separa os sujeitos (Baitello Júnior, 2012). Entendemos que o acontecimento comunicacional definido por Marcondes Filho se aproxima da ideia de comunicação poética, na qual forma e conteúdo se apresentam de modo indissolúvel. Trata-se de um processo comunicacional polissêmico e caracterizado pela complexidade, no qual todos os elementos são elementos de sentido (Silva, 2010). O poético, amparado pelo princípio "com" (Dravet; Castro e Silva, 2006, 2007), talvez possa dizer sobre a morte, ao criar imagens capazes de suscitar uma perspectiva complexa dos fenômenos. Neste contexto teórico, partimos das seguintes questões: Como se constituem as representações da morte nas narrativas? Quando materializadas em representações poéticas, podem caracterizar uma comunicação poética? Que imagens se encontram por trás das imagens poéticas da morte, ou seja, quais são as entrelinhas e os intertextos presentes nessas representações? Como rompimento com o cotidiano, a morte é a suspensão da própria narrativa? Uma comunicação poética seria uma forma de religação?

\section{A incomunicabilidade e o artifício da poesia como possibilidade de comunicação}

Para pensar a comunicação de forma poética, propomos um movimento similarà compreensão de Dravet e Castro e Silva (2006), para quem“o pensamento profundo sobre algo só o é na medida em que possui conexões autoprodutoras e auto-realizadoras em si mesmo. O pensar profundo é o pensar amorosamente, isto é, o pensar que adota o princípio da religação ou princípio com" $(2006$, p. 6).

Vilém Flusser define a comunicação entre humanos comoartificial, pois nos comunicamos por meio de códigos aprendidos culturalmente (2007), o que nem sempre é consciente, pois ao aprendermos um código, tendemos a naturalizá-lo:

Sob a perspectiva da "natureza", o homem é um animal solitário que sabe que vai morrer e que na hora de sua morte está sozinho. Cada um tem de morrer sozinho por si mesmo. E, potencialmente, cada hora é a hora da morte. Sem dúvida, não é possível viver com esse conhecimento da solidão fundamental e sem sentido. A comunicação humana tece o véu do mundo codificado, o véu da arte, da ciência, da 
filosofia e da religião, ao redor de nós, e o tece com pontos cada vez mais apertados, para que esqueçamos nossa própria solidão e nossa própria morte, e também a morte daqueles que amamos (Flusser, 2007, p. 91).

Morin (1997) expõe a morte em uma articulação bio-antropológica, como o traço mais humano,"mais cultural do anthropos"(1997, p.16). Para ele, a angústia humana da morte provoca reações mágicas, tabus, presságios que culminam nas religiões, na cultura. A comunicação, para Flusser (2007), é fruto desta angústia.

Ciro Marcondes Filho explica que a comunicação vai além da linguagem estruturada em uma língua, pois se faz em formas menos codificadas: o silêncio, o toque, os ambientes, a "fala não linguística do outro", pois "na origem da civilização, não está a fala, mas os sentimentos. Eles é que deram origem aos primeiros contatos entre humanos, e deles, como um subproduto abstrato, impessoal, neutro e desvinculante, surgiu a língua estruturada" (Marcondes Filho, 2004 , p. 83). Afirma que não podemos nos prender às palavras para captarmos o mundo, pois estas são um meio pouco confiável de comunicação, visto que podemos controlar aquilo que emitimos, empenhando-nos para construir uma boa imagem, deixando expresso apenas por outros canais o que somos de fato (Marcondes Filho, 2004, p. 93).

Para Norval Baitello Júnior, a matéria-prima da comunicação é o afeto, constituidor de vínculos. Afeto é a palavra latina para "pathos", do grego, que abarca sentimentos tanto positivos quanto negativos (informação verbal)2.

Contraponto da comunicação, a incomunicação (Marcondes Filho, 2004, p. 93) está presente em uma suposta "sociedade da comunicação". Os sistemas midiáticos de rádio, televisão, jornais, revistas, difundem mensagens, mas não comunicam. Cumprimentamo-nos diariamente, mas isto não significa comunicar. A ideia de que nos comunicamos mais e melhor com o advento das tecnologias éoposta à tese defendida por Marcondes Filho, uma vezque, para ele, estas tecnologias apenas iludem. Nesse mesmo sentido, Baitello Júnior afirma:

\footnotetext{
Quanto mais se aperfeiçoam os recursos, as técnicas e as possibilidades que o homem tem de se comunicar com o mundo, com os outros homens e consigo mesmo, aumenta também, em idêntica proporção, as suas incapacidades, suas lacunas, seu boicote, seus entraves ao mesmo processo, ampliando um território tão antigo quanto esquecido, o território da incomunicação humana. Assim, andam de mãos dadas e crescem juntas, como irmãs gêmeas, a comunicação e a incomunicação (Baitello Júnior, 2002, p. 1).
}

2 Fala ministrada pelo autor na Conferência de abertura do IX Encontro de Pesquisadores em Comunicação e Cultura da UNISO em 26 de Outubro de 2015. 
Para Baitello Júnior, ao contrário do que se possa pensar, é nos excessos que a incomunicação se faz presente. Desta forma, rompemos os vínculos com os outros e conosco; o que fica no lugar são os fantasmas dos vínculos, aos quais Baitello Júnior chama de "incomunicação".

No excesso de informação, no excesso de tecnologia, no excesso de luz, no excesso de zelo, no excesso de visibilidade, no excesso de ordem. Vivemos (e morremos) nos excessos do tempo e no tempo dos excessos. Os excessos do tempo trazem, por um lado, a aceleração, o estresse, a pressa, por outro, a desocupação, o desemprego, o tempo esvaziado. E o roubo do tempo: o tempo de vida que nos é roubado pelas cidades e seus excessos ou pela mídia e suas hipérboles (Baitello Júnior, 2002, p. 2).

Marcondes Filho expõe que apesar do excesso de comunicação e, talvez, por causa dele, as pessoas continuam a achar que não há troca, que é "difícil passar ao outro o que a gente sente, como a gente sente, as coisas que estão dentro da gente" (Marcondes Filho, 2004, p. 7), portanto, afirma, tentamos preencher o que dificilmente será preenchido: a separação entre as pessoas.

A esta ideia podemos comparar a de Baitello Júnior, que fala da existência de um abismo entre o "eu e o outro", e das tentativas de preenchê-lo: "Com os gestos, com a voz, com os rastros (olfativos, visuais, auditivos ou táteis), com as imagens arcaicas, com escritas de todos os tipos, com as imagens produzidas por máquinas e até mesmo com as próprias máquinas de imagens" (Baitello Júnior, 2012, p. 60). A esta atividade, a de construção de pontes sobre o abismo, o autor dá o nome de comunicação, na qual as pontes seriam as mídias. Acredita ser este um trabalho insano, em que temos apenas"lampejos de um fugaz preenchimento, pontes fugazes que nos levam até o outro, transpondo por breves relances o vazio do abismo" (Baitello Júnior, 2012, p. 60). A ideia parece se aproximar do conceito de acontecimento comunicacional, para Marcondes Filho, que defende a comunicação como evento improvável, único, um acontecimento que precisa constituir novos sentidos. Ressalta que a comunicação vai além dos signos, fazendo-se presente na relação sensível com o mundo, o que exige uma abordagem mais fenomenológica do que linguística, e propõe o Metáporo, ou quase-método. Construindo um panorama da ciência clássica, aponta que essa sempre se ocupou da observação de movimentos regulares, daquilo que se repete de forma constante, ignorando os demais fenômenos que fogem a essa premissa. Para ele, apenas 10 a 15\% dos fenômenos da natureza apresentam essa continuidade, sendo que o restante é totalmente irregular. Essa postura científica obteve sucesso com relação às demais pelo fato de que em nosso pensamento ocidental temos a predileção por conceitos como a verdade e a certeza, que são pensamentos metafísicos (Dantas, 2012). 
Esta postura de Marcondes Filho, a mesma adotada, aqui, por nós, parece convergir para o pensamento de Flusser (2007), que discorre sobre a metodologia na pesquisa em comunicação em uma perspectiva interpretativa, oposta à explicativa, típica das ciências naturais. Para ele, não se pode falar em uma "condição efetiva das coisas", e sim, que esta diferença se dá no posicionamento do pesquisador (Flusser, 2007, p. 92). Entende a teoria da comunicação como uma disciplina interpretativa, diferindo da "teoria da informação" ou da "informática", através de uma abordagem da comunicação humana como um "fenômeno significativo a ser interpretado" (Flusser, 2007, p. 92). Desenvolve a ideia de que a comunicação humana é inatural e até contranatural, visto que o ser humano encontrou formas possíveis para o acúmulo das informações adquiridas, e discute a intencionalidade, o "propósito humano". Este acúmulo de informações, de geração em geração, que caracteriza a comunicação humana, não é visto como obra do acaso, mas como um fenômeno da liberdade:

(...) a comunicação humana aparece aqui como propósito de promover o esquecimento da falta de sentido e da solidão de uma vida para a morte, a fim de tornar a vida vivível. Esse propósito busca alcançar a comunicação, na medida em que estabelece um mundo codificado, ou seja, um mundo construído a partir de símbolos ordenados, no qual se represam as informações adquiridas (Flusser, 2007, p. 96).

A intencionalidade, discutida na Fenomenologia, também é incorporada à definição de comunicação de Marcondes Filho:

Comunicação é um acontecimento que tem a ver comigo e como me relaciono com o outro e com as coisas; é, portanto, uma forma de relação que eu desenvolvo com o mundo circundante. A comunicação só acontece quando eu me volto a esse mundo e transformo meros sinais em comunicação e/ou informação de acordo com a minha intencionalidade (Marcondes Filho, 2008b, p. 19).

Sobre as formas de comunicação, Flusser (2007) fala sobre uma dialógica e outra discursiva. Na primeira, os seres humanos trocam informações diferentes com o intuito de síntese, criação de uma nova informação. $\mathrm{Na}$ discursiva, preservam-se as informações já existentes, esperando que estas, uma vez compartilhadas, resistam ao efeito entrópico da natureza. Uma não existe sem a outra e, para que ocorra um diálogo, é preciso que tenha havido a recepção anterior de discursos, assim como para a produção destes é preciso que tenha sido produzido um diálogo anterior. Para o autor, somente quando há o equilíbrio entre as duas formas, discurso e diálogo, é que a comunicação alcança seu objetivo de superar a solidão humana e dar significado à vida. Para 
o autor, a incomunicação se dá não apenas devido aos excessos, mas também pela forma como a comunicação se realiza: na predominância dos discursos.

Se para Flusser a comunicação é a tentativa de driblar a morte, esta poderia ser associada à incomunicação. Morin (1997) afirma que a ideia da morte contém um vazio infinito. Nele, está o"impensável, o inexplorável, o não sei quê conceptualquecorrespondeaonãoseiquêcadavérico.Elaéa ideia traumática por excelência" (1997, p. 33). Neste sentido, como comunicar o incomunicável? Seria a comunicação poética um modo compreensivo de representar a ideia da morte?

\section{Sobre "Um conto chinês"}

Um Conto Chinês (Um Cuento Chino, 2011, Argentina / Espanha), dirigido por Sebastián Borensztein, é protagonizado por Ricardo Darín, Muriel Santa Ana e Ignacio Huanga, com locações em Buenos Aires (Argentina) e em Ciudad de la Luz (Alicante, Espanha). Recebeu os prêmios de melhor filme e prêmio do público no Festival de Cinema de Roma e melhor filme hispano-americano do prêmio Goya de 2011. Conta a história de Roberto (Ricardo Darín) e Jun (Ignacio Huanga), unidos pelo acaso. Roberto, veterano da Guerra das Malvinas, tem sua vida marcada pela rotina, solidão, dificuldade em estabelecer vínculos, obsessão pelo passado, laços afetivos mais com os mortos que com os vivos.

A ruptura de seu cotidiano se dá no encontro com Jun, um chinês perdido em Buenos Aires, marcado pela tragédia da morte da noiva e em busca de seu único parente, um tio, imigrante chinês, morador da cidade portenha.

Jun é atirado de um táxi, após ser roubado, e por acaso encontra Roberto, que observa a cena e, sem saber falar a língua do chinês, é obrigado a ajudar o rapaz, que não sabe espanhol. Roberto, que pouco se comunica, durante $o$ convívio forçado com o estrangeiro, do qual tenta se livrar de diversas maneiras, busca distintasformas de comunicação. Oacasotransforma incomunicabilidade em tentativa de comunicação, não apenas de Roberto para com Jun, mas também do argentino com outras pessoas a quem é forçado a recorrer, a exemplo do policial em uma delegacia e do funcionário da embaixada da China.

Para uma interpretação possível das representações da morte nesta narrativa, passamos à leitura, cientes de que o ler envolve recortar, portanto, selecionar alguns possíveis e excluir outros. Nossa metodologia consistiu em assistir ao filme, pontuando os elementos de maior impacto, em uma perspectiva fenomenológica, que preferimos chamar de "metáporo", tal como Marcondes Filho (2008a). Buscamos desvelar aspectos poéticos da narrativa fílmica, entendida aqui como mídia, ou seja, como ponte para a mediação, interpretação, crítica e construção complexa dos fenômenos concretos. 
Assistimos ao filme anotando os elementos de maior peso dramático. Assistimos a uma segunda vez, observando aspectos estéticos, tais como o uso da cor, enquadramentos, elementos de cena, figurino e ambientação. À medida que descrevemos as sequências, pontuamos aspectos narrativos: Personagens, Enredo, Narrador, Tempo, Espaço. Somada à análise da narrativa, é realizada a leitura dos aspectos poéticos, entendidos como "qualidade da linguagem" (Silva, 2007, 2010, 2012), criativa e criadora, capaz de comunicar por meio do sensível (Silva, 2007). Também associamos o poético ao conceito de Lotman (1978) para o texto artístico, construído com complexidade, no qual todos os elementos são elementos de sentido e que, de modo econômico e denso, transmite um grande volume de informações, por meio de uma estrutura modelizante (cria um modelo de linguagem; materializa em linguagem um fenômeno concreto; cria um novo modelo de mundo, modelizando o olhar do fruidor). As estruturas modelizantes são compostas por invariantes e variantes, que são traduzidas e absorvidas na memória do sistema. O texto artístico se faz por meio de variantes, mais do que de invariantes. As invariantes são as formas já absorvidas pelo sistema, que permitem a identificação de modelos conhecidos. As variantes são rupturas da linguagem, ainda não absorvidas pelo sistema, e que provocam estranhamento. Defendemos que as formas variantes, constituintes dos textos artísticos, ou da linguagem poética, são propiciadoras do acontecimento comunicacional, definido por Marcondes Filho (2004).

Um Conto Chinês inicia com a informação verbal: História Baseada em Fatos Reais, o que explicita o absurdo da vida comum, que, percebido, recortado e interpretado, pode ser o mote tanto para uma narrativa ficcional quanto para a concretude da notícia, realidadequenestecaso inspirou ofilme, um fato noticiado.

O enredo apresenta, já na introdução, o ponto de conflito mais alto da narrativa, a ruptura do cotidiano por meio da morte: Jun encontra-se com a noiva, em um barco, não se sabe qual é o tempo, mas o espaço é um lago bucólico onde há apenas o casal. Ele está de vermelho e branco; o vermelho, segundo Chevalier e Gheerbrant (2007), tanto pode representar a vida quanto a morte, e se alimenta da ambiguidade do fogo, que aquece e queima; a noiva está de verde e branco: o verde é a cor que equilibra as emoções (Chevalier e Gheerbrant, 2007), já o branco pode representar os dois extremos da gama cromática, evocando o fim e começo, mas também a revelação (Chevalier e Gheerbrant, 2007). Vermelho, verde e branco, presentes na primeira cena, serão as principais cores ao longo da narrativa, funcionando não apenas como modeladores da estrutura visual, mas também como estratégias poéticas para a produção de sentidos, ao conotarem as emoções dos personagens, que 
transitarão entre o amor, a morte, a angústia, a solidão, o encontro, a revelação e a busca por equilíbrio e vida.

Jun canta para a noiva; sorriem, e ele vai ao fundo do barco, onde abre uma caixa com duas alianças. É então que uma vaca cai de um avião e mata a noiva de Jun. A vaca possui muitos significados, mas são recorrentes aqueles associados à maternidade, à fecundidade, à riqueza e à renovação (Chevalier e Gheerbrant, 2007), sentidos estes que serão perceptíveis no transcorrer da narrativa.

Na sequência, um corte seco leva para uma imagem de ponta cabeça, em plano geral, que, virando aos poucos, como um recurso poético, mostra a Casa de Ferragens de Roberto, na cidade de Buenos Aires, uma metáfora para a mudança de espaço da narrativa, que passa da China para a Argentina, do Oriente ao Ocidente. Segue um zoom, do espaço externo para o interno, até Roberto, atrás do balcão, contando pregos de uma caixa, uma de suas manias. A história, daqui para frente, está centrada mais na descrição dos personagens do que no desenvolvimento do enredo. As ações servem para construir um quadro sobre a personalidade de Roberto: obsessivo (na repetição de contar os pregos das caixas), indiferente na tentativa de diálogo com o outro (maltrata clientes, responde de forma curta e rude), e quando no interior da casa onde vive, cultua a foto da mãe, exposta em uma cristaleira carregada de bibelôs, comprados por ele, como presentes ofertados à morta. Na intimidade e solidão, sua expressão verbal se amplia, mas fala com os mortos e sozinho (enquanto cozinha, remói os diálogos não estabelecidos ao longo do dia, repetindo perguntas feitas por um cliente e oferecendo respostas rudes que poderia ter dado e não deu). Sua casa e suas roupas possuem tons de cinza ou verde militar, indícios para a futura justificativa sobre sua personalidade, afetada pelo trauma vivido na guerra.

O contraponto de Roberto, enquadrado em ambientes interiores, está em Mari, cujos enquadramentos em primeiro e primeiríssimo plano a exibem no exterior: iluminada, sorridente, olhos arregalados e perceptivelmente apaixonada por Roberto, que resiste a se relacionar com ela.

Outro importante dado do espaço está no fundo da residência de Roberto, um quintal com um amontoado de inutilidades, para as quais ele chama uma caçamba, o que indica o intento de remover o lixo, análogo das emoções e memórias das quais ele parece querer se livrar, sem sucesso.

$\mathrm{Na}$ sequência seguinte, o enquadramento, na parte inferior da tela, composta por flores vermelhas, simula uma meia moldura, sobre a qual aparece o rosto de Roberto ao lado de uma vendedora, e, em seguida, ele entrando em um cemitério com um buquê de flores vermelhas, que trazem a vida (flores) e a morte (os túmulos, incluídos os de seus pais). 
De volta ao interior da casa, Roberto lê o jornal e se detém em uma notícia sobre o destino de dois amantes: escondidos em um carro, acabam despencando de um penhasco, porque a mulher abaixa acidentalmente o freio de mão com o pé. Ao ler a notícia, Roberto se transporta para o lugar dos personagens, rindo e imaginando-se com Mari, no lugar da amante. Saberemos que ele coleciona notícias bizarras, que quando lidas por ele, resultam no momento em que ele mais se descontrai. Ao imaginar-se nessas notícias, como protagonista, as cores tornam-se vibrantes, com ênfase ao vermelho e ao verde, como se o cotidiano de Roberto fosse mais obscuro, sombrio e frio do que as notícias que lê, coloridas e divertidas, apesar de todas resultarem nas mortes trágicas dos personagens.

A quebra da normalidade no cotidiano de Roberto ocorre quando ele, sentado do lado de fora de seu carro, observa aviões que pousam e decolam. Ele coleciona aviões em miniatura, pois há uma destas pendurada no retrovisor do carro e muitas outras decorando uma prateleira de sua casa, fato que se revelará como um índice (somado à cor verde militar de suas roupas e de sua casa) da explicação sobre sua personalidade. Observando os aviões, Roberto percebe um chinês, que é jogado de um táxi, e inicia uma tentativa precária e desesperada de pedir ajuda. Roberto, apesar de não falar o idioma, entende que o rapaz foi assaltado e que procura por alguém, pois ele mostra um endereço tatuado em seu braço. A contragosto e esbravejando palavrões, coloca o chinês em seu carro. Enquanto dirige, Jun passa mal e vomita. Roberto, enojado e furioso, atira o chinês para fora. Mas chegando em casa, ao sentar-se para comer, sente remorso e volta, a fim de buscá-lo, o que permite ao espectador notar o contraditório de sua personalidade aparentemente fria. Percebe, ao retornar, que Jun está no mesmo lugar; leva-o para uma delegacia, onde não se entende com o policial, que queria colocar Jun em uma cela, com o que Roberto não concorda. Agride o policial com uma cabeçada e vai embora com Jun, oferecendo-lhe, já em sua casa, ducha, comida e cama.

Conhecendo-se a personalidade complexa de Roberto, menos plana que no início do filme, o enredo passa agora às ações, mais que descrições, e se volta para a relação dele com o chinês: no café da manhã, Jun imita os gestos de Roberto com o pão.

Roberto vai à embaixada da China com Jun e descobre, falando com um funcionário, que o chinês, órfão, está em busca de um tio que vive em Buenos Aires. A embaixada promete procurar o tio, mas não pode dar abrigo a Jun, o que provoca desespero em Roberto, que foge, abandonando Jun na porta da embaixada. Roberto segue poucos metros com seu carro, verde oliva, e, repentinamente, volta, de ré e abre a porta, pela qual Jun entra rapidamente. 
Roberto sente-se desorientado com a presença do chinês, que, à mesa, olha fixamente para Roberto. Já é possível perceber que, ao contrário do argentino, Jun é receptivo, afável, interessado. Roberto fala ao chinês, em tom de lamento e indignação: "Não estou acostumado a ter companhia", reconhecendo sua rotina solitária. Na tentativa de resolver a situação, vai com Jun ao comércio chinês de Buenos Aires, onde interpelam, sem sucesso, vários vendedores, em busca do tio de Jun. Ao tentarem falar com um ancião, este diz a Roberto que não entende nada das palavras de Jun, ao que Roberto apela: "Mas você é chinês, ele é chinês". E a resposta é: "Ele fala mandarim, eu, cantonês; são línguas diferentes". Roberto diz um palavrão, e o idoso o expulsa da loja dizendo: "Isso eu entendo". A mesma nacionalidade não garante a comunicação entre os chineses, e o fato do velho chinês entender espanhol também não garante o contato e a empatia com Roberto, mostrando que a comunicação está além das palavras.

Voltando à casa, Roberto lê o jornal, observado por Jun. A notícia que chama a sua atenção conta a incrível morte de um barbeiro e seu cliente, causadas na colisão de um carro carregado de barras de aço, que, em plano-sequência, perde o freio, em alta velocidade; uma barra atravessa o vidro da barbearia, acerta a cabeça do barbeiro que, com a navalha em punho, acaba cortando o pescoço do cliente. Roberto, rindo, imagina-se no lugar do barbeiro e, no do cliente, o sujeito mais inconveniente que costuma comprar na Casa de Ferragens. A cena é bastante iluminada, e as cores, vibrantes. O barbeiro, agora na pessoa de Roberto, usa amarelo e, ao cortar a garganta de seu cliente, o sangue jorra abundante e de um vermelho muito vivo. Aqui a morte, mais uma vez, é pintada por um viés cômico e, paradoxalmente, vivo, vibrante, inusitado, quase feliz.

Mari vem à Casa de Ferragens, convida Roberto para jantar, que resiste e tenta declinar pelo fato de estar hospedando o chinês. Mari, resoluta, pede a ele que leve o rapaz, o que deixa Roberto mudo. Nota-se que é a personagem com a qual Roberto nunca é rude, mas também a que o deixa mais sem palavras, pois este nunca completa uma frase quando tenta dialogar com ela. Aqui a incomunicabilidade assume outra forma, não a da solidão ou da ausência de empatia, mas a da profunda empatia e afeto que não se exprimem com facilidade.

No jantar, participam a irmã e cunhado de Mari; comem, riem e conversam, estabelecendo com Jun um vínculo que passa pelo compartilhar a refeição, os gestos, o tom de voz, a atmosfera de interesse. Jun sorri ao perceber os olhares de Mari para Roberto.

Mari, após a refeição, mostra fotos a Jun, o que estabelece um entendimento cúmplice entre ambos, levado a cabo pelas imagens, entre as quais está a de uma vaca, no sítio onde Mari vive, imagem esta que aciona a 
memória da dor de Jun, que ao chegar à casa de Roberto, retira de um envelope vermelho uma foto da noiva morta.

Jun passa a realizar pequenos trabalhos para Roberto, solicitados como desculpa para que ele se desocupasse de estar com o chinês, tais como retirar as coisas acumuladas do quintal e colocá-las na caçamba. Aqui há outra metáfora, pois Jun será o responsável por retirar o peso morto da memória e a dor da vida de Roberto. Começa a pintar as paredes do quintal de branco (cor da revelação, da purificação). Mari vai até a Casa de Ferragens, pede a Roberto que chame Jun para passear com ela e afirma, ao fim do dia: "Nunca pensei que pudesse me divertir tanto com alguém sem entender uma palavra". Entre ela e Jun se estabeleceu o afeto. Mari pede comida chinesa, e com a presença do entregador, tem a ideia de usá-lo como tradutor para saberem parte da história de Jun, que pergunta o nome de Roberto e agradece por tudo o que fizeram por ele. Com este mediador, ocorre o primeiro momento de comunicação verbal, ainda que indireta.

No dia seguinte, na Casa de Ferragens, Roberto ouve um estrondo e descobre que, ao carregar entulho para a caçamba, Jun quebrou a cristaleira, que representa um forte vínculo com o passado, como parte de um ritual de colecionismo que reforça a relação de Roberto com a memória da mãe. Outra metáfora: o móvel quebrado por Jun desvincula Roberto do mundo dos mortos. Roberto, furioso com o fato, coloca o chinês em um táxi e ordena ao motorista que o deixe no bairro chinês.

Mari, horas depois, sabe que o chinês se foi, e ouve de Roberto: "Algumas coisas são difíceis para mim". E ela responde: "Eu sei. Por isso você não me dá uma chance. E olha que eu falo espanhol". Há um reconhecimento de ambos sobre a incomunicabilidade de Roberto, sobre a insuficiência das palavras. Roberto mais uma vez sente na consciência o fato de ter abandonado Jun. Vai até o bairro chinês, e, casualmente, é observado pelo policial que agrediu na delegacia, ao parar o carro ao lado do dele, no trânsito. O policial persegue-o, e, já a pé, armado, leva-o a um terreno escondido onde pretende espancá-lo. Jun, que pedia comida em um local próximo, vê a cena, vai até o local e salva Roberto, batendo na cabeça do policial com um vaso quebrado, encontrado em um monte de entulhos.

Roberto leva Jun mais uma vez para casa, e, inconformado, tenta encontrar alguma explicação para o fato. Pede comida chinesa, convida o entregador a entrar e inicia um diálogo com Jun, traduzido pelo entregador. Permite então que Jun permaneça em sua casa até que aprenda espanhol e possa arrumar um emprego. Jun pergunta se Roberto tem uma família, e este explica que perdeu a mãe ao nascer, e, o pai, aos 19 anos. Pergunta, em seguida, o que Roberto tanto procura no jornal, e ao ouvir a resposta, Jun indaga sobre o porquê de 
colecionar notícias absurdas. Roberto conta que o pai saiu da Itália para fugir da guerra, mostra uma página de um jornal italiano com uma notícia sobre a guerra das Malvinas e conclui que a notícia em si já seria absurda, mas a foto que estampa a matéria traz o rosto de um soldado, ele, Roberto, que lutou na Guerra das Malvinas, matou e viu morrer amigos, e, derrotado, foi deixado no porto de Buenos Aires. Neste momento se dá a revelação: para Jun e para o espectador: é o que justifica a personalidade de Roberto, que quando retornou da guerra, soube que o pai havia falecido, impactado pela notícia e pela foto do filho no jornal italiano. Roberto fala que "a vida é um grande sem sentido", ao que Jun se contrapõe, dizendo que "há sentido em tudo". Roberto quer provar que nada faz sentido, e mostra as notícias bizarras que coleciona, até que chega a uma da China, em que uma vaca cai do céu sobre um barco com um casal de noivos, matando a noiva. A vaca caíra de um cargueiro e era parte de um carregamento roubado. Jun fica paralisado, e Roberto, sem entender, questiona: "Não é um absurdo???". Depois de um longo silêncio, Jun responde que a notícia é sobre ele e a mulher com quem se casaria. Roberto desespera-se e começa a gritar: "Não é possível". Nesta sequência, é patente que muito em comum une os dois personagens, mas há entre eles uma diferença fundamental. Enquanto Jun procura compreender os fatos, Roberto segue questionando, procurando explicaçõesque nem sempresão possíveis deencontrar, oqueosleva ao raciocínio distinto: tudo tem um sentido, para Jun, e nada faz sentido, para Roberto.

No dia seguinte, Roberto recebe uma ligação do tio de Jun, que vive em Mendoza. Grita por Jun, que incrédulo, conversa com o tio ao telefone, chora, desliga e, emocionado, é consolado por Roberto. Neste momento há uma comunicação profunda entre os dois, que extrapola qualquer diferença ou palavra: o vínculo se fez e não mais será rompido.

No desfecho, Roberto leva Jun ao aeroporto. Volta para casa e, ao cozinhar, não está mais falando sozinho, pois algo mudou. Vai ao quarto onde Jun dormia e encontra dois desenhos feitos por ele: Roberto em luta com um tigre, e Mari ricamente adornada em vestes chinesas.

Roberto saberá, depois, através do cunhado de Mari, que ela partiu. No quintal, percebe que Jun desenhou, com carvão, uma enorme vaca na parede branca. A sequência final mostra Roberto dirigindo por uma estrada. Ao chegar ao destino, depara-se com Mari, em sua casa no campo, ordenhando uma vaca em meio à paisagem verde. 


\section{A interpretação: uma possibilidade}

Sobre a narrativa, pode-se afirmar que se trata de um texto poético, no qual todos os elementos são elementos de sentido. Composta por uma estrutura carregada de simbolismos, no uso das cores, nas referências à morte, nas variantes (a cena de ponta cabeça no início da narrativa), nos contrastes entre as personalidades dos personagens, na presença da vaca no início, meio e fim da narrativa, comunica o enredo de forma sensível, convidando o leitor a montar o quebra-cabeça que revela a história de Roberto e justifica o seu modo de agir.

É possível afirmar que todas as ações são voltadas para a caracterização dos personagens, especialmente de Roberto, o protagonista da trama. Tudo conduz para a compreensão deste personagem: ermitão, incomunicável, agressivo, mal-humorado, solitário e obsessivo; mas, ao mesmo tempo, justo, bom, sensível e honesto.

Roberto começa como um personagem aparentemente plano, no entanto, desenvolve-se carregado de complexidade. Com dificuldades em se relacionar, acaba auxiliando e criando um vínculo com um estranho, que não fala sequer a sua língua. Preso ao passado, foi marcado pela morte da mãe, no seu nascimento; pela guerra, na qual matou e viu amigos serem mortos; pela morte do pai, da qual se torna ciente depois de sua volta das Malvinas. $O$ encontro com Jun, também órfão, como ele, é possibilitado pela morte da noiva do chinês, assim, ambos estão unidos pela solidão, sofrimento e forte presença do passado em suas vidas.

Mari, contraponto de Roberto, é vibrante, expansiva, falante, risonha e aberta ao novo, ao diferente, à vida. Vive o hoje de forma intensa, e ao passo que Roberto reclama de situações e pessoas, Mari procura compreender e aceitar; é a personagem que faz vir à tona o melhor de Roberto.

Jun se constitui pelo silêncio e pelos gestos: pela comunicação que está além do verbal. Um dos recursos poéticos utilizados para isso é a ausência de legendas em todas as situações em que o personagem faz uso do chinês, e, ainda assim, é possível compreender cada um de seus gestos, intenções e desejos, pela expressão do seu rosto, pelo tom de sua voz, pelo olhar, pelas mãos. O espectador participa com Roberto da experiência de não entender a linguagem verbal de Jun, mas de vincular-se a ele. Enquanto Roberto se esforça para ser incomunicável, Jun faz tudo para se comunicar. Juntos, somam suas carências, reforçam seus próprios conflitos para chegar a um ponto de equilíbrio, simbolizado no verde e na vaca com os quais Roberto se depara na cena final, ao chegar à fazenda de Mari. Roberto, antes de Jun, repercutia seu próprio discurso desgastado, de poucas palavras e ações previsíveis: a mesma rotina, o mesmo mau-humor, a mesma aspereza. No encontro com Jun, somam-se as diferenças 
e ocorre a representação do acontecimento comunicacional, que leva a um diálogo efetivo, entre dois modos de ser e de pensar: um não vê sentido em nada; o outro vê sentido em tudo. Cruzam-se Oriente e Ocidente; duas vidas, duas linguagens, duas culturas, duas consciências e um só afeto.

Com a morte da noiva de Jun pela vaca, que cai do céu sobre o barco, o trágico e o cômico se associam. A morte está também nos objetos frágeis que Roberto coleciona e dispõe cuidadosamente na cristaleira, onde está a foto da mãe. A quebra da cristaleira, por Jun, rompe o silêncio de Roberto, a sua profunda incomunicabilidade, apenas superada no acaso do encontro com o chinês, com o qual conseguiu se comunicar de forma profunda por poder ir além das palavras, por precisar ir além delas, tornando-as dispensáveis. As notícias colecionadas por Roberto também envolvem a morte e combinam elementos trágicos e cômicos, que permitem questionar o absurdo do real, o sem sentido da vida. Há a morte, ainda, nas cenas do cemitério, quando Roberto coloca flores no túmulo dos pais. E também nos aviões que coleciona, em suas lembranças de guerra, sobretudo na notícia que pôs fim à vida de seu pai, quando vê publicada em um jornal uma foto do filho para ilustrar a batalha.

A morte pode ser vista, portanto, como o mote condutor da narrativa - é o que une os dois personagens e o que os levará à mudança e à consciência para o recomeço, o retorno à vida. É metáfora e razão da incomunicabilidade, mas também possibilidade de comunicação, ao estabelecer novos vínculos, novos afetos, novas experiências, outras narrativas.

O enredo é circular, com a presença da vaca, que matou a noiva de Jun na primeira sequência do filme, levando-o até Roberto, resgatado para a vida, simbolizada na sequência final: o desenho de uma vaca deixado por Jun na parede do quintal de Roberto, e a vaca ordenhada por Mari na última cena do filme.

As representações da morte, neste filme, constituem-se de modo ambíguo: no trânsito entre o trágico e o cômico, apontam para o fato de que, diante da tragicidade de nossa curta existência, só resta o riso. Onipresentes no cotidiano de Roberto, são formas poéticas de comunicação, por sua complexidade e polissemia, e desvelam um pouco da incomunicabilidade e da angústia resultante da consciência de nosso destino como seres irremediavelmente solitários e mortais. Diferem de outras formas de comunicação por possibilitarem uma compreensão metafórica dos fenômenos concretos, talvez único modo de compreender aquilo para o que a racionalidade é insuficiente.

A narrativa, entendida aqui como forma de mediação, representa o encontro e a vinculação entre os personagens: Roberto, Jun e Mari. Mais do que isto, oferece ao espectador outras possibilidades de compreender o protagonista, ao desvelar o encontro de Roberto com seu passado e consigo mesmo. 
As notícias colecionadas por Roberto, narrativas, estabeleceram-se como um modo de dar organização e sentido ao sem sentido da vida de ambos, dele e de Jun, pois fornecem o elo entre os personagens.

Os aviões, também colecionados por Roberto, presentes na casa e em seu carro, são metáforas para a conexão entre ele, Jun, o passado e o presente de ambos: o avião traz a vaca que mata a noiva de Jun e o obriga a partir para a Argentina; rememora o passado de Roberto, na relação com a guerra; está no presente de Roberto, que observa aviões no lugar onde está quando Jun é jogado do táxi; leva Jun para o encontro com seu tio em Mendoza, partida que obriga Roberto a rever sua própria vida. O poético opera aqui como "princípio com", força motora que dá sentido ao que aparentemente não o tem.

A vaca, presente em toda a narrativa, representa, para os vedas, segundo Chevalier e Gheerbrant (2007), o arquétipo da mãe fértil, papel cósmico e divino, o que parece levar à morte que propicia, aos dois personagens, um renascer. No Tao-te-king, a vaca "é a fêmea misteriosa, o princípio feminino, origem do céu e da terra; vaca branca relacionada ao fogo sacrificial" (Chevalier e Gheerbrant, 2007), conotando a jornada que trará à tona o melhor de Jun e Roberto. No Budismo, relacionada ao processo gradativo que conduz à lluminação, a vaca passa do preto ao branco e quando desaparece, o homem escapa das limitações da existência individual (Chevalier e Gheerbrant, 2007).

O tigre, relacionado a Roberto no final da narrativa, pelo desenho de Jun, pode representar as qualidades que até então não revelara: a força, a coragem, a vontade que faltavam para que ele se libertasse. É o que ocorre aos dois, Roberto e Jun, mas a Roberto, especialmente, que se desprende de sua condição solitária e individualista, num rompante de comunicabilidade e alteridade, um acontecimento comunicacional, que proporcionará criar vínculos com os outros e, em consequência, com o viver, para além da morte, apesar dela, para além das palavras e apesar ou na falta delas.

Como forma mediadora, esta narrativa comunica aos fruidores, de modo poético, a necessidade do encontro, da empatia e da resiliência diante do que se configura inexplicável, mas que a compreensão revela como possível de ser vivido, rememorado e transformado em experiência para se tecer novas histórias. Como forma de reconexão, a narrativa resta como esforço para ultrapassar a morte. 


\section{REFERÊNCIAS}

BAITELLO JÚNIOR, N. As Irmãs Gêmeas: Comunicação e Incomunicação. Tribuna do Norte, 2002.

O pensamento sentado: sobre glúteos, cadeiras e imagens. São Leopoldo: Unisinos, 2012.

BAITELLO JÚNIOR, N. Conferência de abertura do IX Encontro de Pesquisadores em Comunicação e Cultura da UNISO. Sorocaba: Universidade de Sorocaba. 2015.

CHEVALIER, J. e GHEERBRANT, A. Dicionário de símbolos. Rio de Janeiro: José Olympio, 2007.

DANTAS, E. Metáporo e o conceito de comunicação como Acontecimento. Anais do XVII Congresso de Ciências da Comunicação na Região Sudeste. Ouro Preto: Intercom - Sociedade Brasileira de Estudos Interdisciplinares da Comunicação, 2012.

DRAVET, F. M. e CASTRO e SILVA, G. 0 pensamento comunicacional mediante o pensamento poético. Disponível em: http://www.intercom.org.br/papers/ nacionais/2006/resumos/R1592-1.pdf. Acesso em: 23 nov. 2016.

. A mediação dos saberes e o pensamento poético. Revista Famecos, v. 14, n. 32, p. 71-77, abr. 2007.

FLUSSER, V. O mundo codificado. São Paulo: Cosac \& Naify, 2007.

LOTMAN, I. A estrutura do texto artístico. Lisboa: Estampa, 1978.

MARCONDES FILHO, C. Até que ponto, de fato, nos comunicamos? São Paulo: Paulus, 2004.

. Para entender a comunicação: Contatos antecipados com anova teoria. São Paulo: Paulus, 2008a.

. Comunicação, uma ciência anexata e contudo rigorosa. In: Comunicação novo objeto, novas teorias? Teresina: EDUFPI, 2008b.

Michel Serres e Os Cinco Sentidos da Comunicação. Revista Novos Olhares, v. 8, n. 16, p. 5 - 19, 2005. Disponível em: http://revistanovosolhares.wordpress. com/2008/11/06/michel-serres-e-os-cincosentidos-da-comunicacao-de-ciromarcondes-filho/. Acesso em: 28 ago. 2011.

MORIN, E. O homem e a morte. Rio de Janeiro: Imago, 1997.

SILVA, M. C. C. Comunicação e cultura antropofágicas: mídia, corpo e paisagem na erótico-poética oswaldiana. Porto Alegre / Sorocaba: Sulina / Eduniso, 2007. 
Contribuições de luri Lotman para a Comunicação: sobre a complexidade do signo poético. In: Teorias da Comunicação: trajetórias investigativas.1. ed., Porto Alegre: Edipucrs, 2010.

. Sobre o poético e o hipertexto - por uma linguagem da complexidade em sala de aula. In: Cotidiano escolar e tecnologias - tendências e perspectivas, 1. ed., Campinas / SP: Alínea, 2012.

UM CONTO CHINÊS. Direção: Sebastián Borensztein. Produção: Axel Kuschevatzky, Ben Odell, Gerardo Herrero, Juan Pablo Buscarini, Pablo Bossi. Argentina, Espanha: Pampa Films, Tornasol Films e Telefe. 2011.

Professora no Programa de Pós-Graduação em Comunicação e Cultura da Universidade de Sorocaba (UNISO). Doutora em Comunicação e Semiótica pela PUCSP. Estágio pós-doutoral pela PUCRS. Programa de Pós-Graduação em Comunicação e Cultura da Universidade de Sorocaba (UNISO). 